\title{
DIVERSIDADE CULTURAL NAS AULAS DE EDUCAÇÃO FÍSICA NA ESCOLA PÚBLICA: O EMBATE COM IGREJAS CRISTÃS QUANDO SE TRATA DE ESTUDAR CULTURAS AFRICANAS E INDÍGENAS
}

Bruno Rodolfo Martins ${ }^{\mathrm{i}}$

A questão central desse texto é sobre como o tema diversidade cultural pode estar integrado às propostas de intervenções pedagógicas nas aulas de Educação Física escolar, indicando mudanças nas próprias referências que baseiam estas aulas e fazendo emergir questões como o preconceito diante de expressões culturais com referencias africanos ou indígenas. Não se trataria apenas de diversificar conteúdos, mas sim de oportunizar o conhecimento e a valorização desses outros referenciais culturais, fato negado e marcado pela própria história deste componente curricular no Brasil, diante desses referenciais culturais não-europeus. Com isso, questões teóricas e metodológicas da Educação Física escolar estariam sendo revistas, problematizadas e outras, propostas. Contudo, por essa perspectiva, toda a estrutura escolar estaria sendo questionada, especialmente em seu teor políticopedagógico. Com base no caso exemplar que foi usado para esse estudo, haveria resistência em lidar com essa temática por todos os segmentos escolares; em especial, esta resistência é demonstrada por preconceitos, como também certa negligência por parte do corpo pedagógico. Ao fundo, religiões cristãs, notadamente aquelas organizadas institucionalmente enquanto Igrejas, demonstram seu poder de manutenção de suas visões de mundo, direta ou indiretamente, mantendo também essa dominância na escola pública. O debate culmina e atravessa, por um lado, na necessidade de uma escola pública efetivamente laica e, por outro, a influência na Educação de setores religiosos cristãos.

\section{A Diversidade Cultural e os Documentos Oficiais}

A diversidade cultural "refere-se à multiplicidade de formas pelas quais as culturas dos grupos e sociedades encontram sua expressão. Tais expressões são transmitidas entre e dentro dos grupos e sociedades" (UNESCO, 2005, p.6), conforme a Convenção sobre a proteção e a promoção da diversidade das expressões culturais, da UNESCO, da qual o Brasil é signatário. No entanto, tanto o debate quanto as ações voltadas para a valorização, em termos gerais, das diversas expressões culturais brasileiras não são algo tão recentes, vide as chamadas missões folclóricas no inicio do século XX. Conforme Toni (2011), "a Missão de Pesquisas Folclóricas, projeto do Departamento de Cultura idealizado por Mário de Andrade 
com as colaborações de Oneyda Alvarenga e Dina Lévi-Strauss, teve seu embrião em 1928, na fase mais intensa da vida do pesquisador de campo" (p.1). A viagem da Missão foi organizada por ele e realizada em $1938^{\mathrm{ii}}$. Contudo, foi somente a partir da Constituição Brasileira de 1988, que a preocupação com a diversidade cultural do Brasil ficou mais evidente, conforme podemos observar em seu Artigo 215:

(...) O Estado garantirá a todos o pleno exercício dos direitos culturais e acesso às fontes da cultura nacional, e apoiará e incentivará a valorização e a difusão das manifestações culturais.

$\S 1^{\circ}$ - O Estado protegerá as manifestações das culturas populares, indígenas e afro-brasileiras, e das de outros grupos participantes do processo civilizatório nacional (BRASIL, 1988, p.71).

Percebe-se já naquele momento que o Estado não só se prepara para valorizar diversas manifestações culturais, mas também que muitas destas compõem expressões culturais normalmente marginalizadas por uma parcela poderosa da sociedade, e que, ao longo da história da sociedade brasileira, foram muitas vezes reprimidas sistematicamente pelo próprio Estado (como é o caso do samba, da capoeira e do candomblé, exemplos de expressões africanas construídas em território brasileiro). E a partir deste texto constitucional, "o Estado protegerá" e "incentivará a valorização" destes referenciais culturais - também constituintes culturais do Brasil.

Uma das formas que o Estado consolidou estas ações foi através da Educação, anos depois da entrada em vigor da atual Constituição, com a elaboração da Lei de Diretrizes e Bases da Educação Nacional (LDB - Lei no 9.394, de 20 de dezembro de 1996), quando indicou que o currículo escolar, ou, "ao menos", o ensino de história do Brasil precisaria considerar "as contribuições das diferentes culturas e etnias para a formação do povo brasileiro, especialmente das matrizes indígena, africana e europeia", como consta no $\S 4^{\circ}$ de seu artigo 26 (BRASIL, 1996). Com a Lei 10.639, já em 2003, o texto deste artigo foi alterado, passando a especificar algumas questões com relação às culturas negras e africanas:

$\S 1$ o O conteúdo programático a que se refere o caput deste artigo incluirá o estudo da História da África e dos Africanos, a luta dos negros no Brasil, a cultura negra brasileira e o negro na formação da sociedade nacional, resgatando a contribuição do povo negro nas áreas social, econômica e política pertinentes à História do Brasil (BRASIL, 2003, p.1).

De encontro ao texto, que deixa a questão de certa forma "aberta", da $L D B$, a lei n 10.639 "fecha" e especifica, valorizando a questão africana, justamente o legado cultural mais 
discriminado e invisibilizado na escola e nos currículos de diferentes componentes. De maneira similar, efetivando outros anos de luta contínua, em 2008, este texto é novamente atualizado com a promulgação da $\operatorname{Lei} n^{\circ} 11.465$, reforçando a questão indígena:

$\S 1^{\circ} \mathrm{O}$ conteúdo programático a que se refere este artigo incluirá diversos aspectos da história e da cultura que caracterizam a formação da população brasileira, a partir desses dois grupos étnicos, tais como o estudo da história da África e dos africanos, a luta dos negros e dos povos indígenas no Brasil, a cultura negra e indígena brasileira e o negro e o índio na formação da sociedade nacional, resgatando as suas contribuições nas áreas social, econômica e política, pertinentes à história do Brasil (BRASIL, 2008, p.1).

Diante de todo esse movimento de valorização desses referenciais culturais, no que tange aos discursos legais e oficiais, houve uma provocação para que intervenções pedagógicas começassem a ser revistas, questionadas e reelaboradas, tentando incluir em suas intenções e práticas as questões demonstradas há pouco (agora com suporte legal) - com maior ênfase em algumas áreas e componentes e em outros, menos. Por exemplo, isto foi mais procurado para ser trabalhado “em especial nas áreas de Educação Artística e de Literatura e História Brasileiras", conforme tendência destacada pelo trecho do $\S 2^{\circ}$ dessas duas leis, como se fosse tarefa exclusiva dada a estas, ou como se outras áreas não precisassem desenvolver intervenções neste sentido ou tivessem menos importância para tal tarefa. Contudo, sabemos que nada deve estar desconectado ou isolado no âmbito escolar e que existe uma evidente integração entre os componentes e currículos (ao menos, em teoria). Nessa perspectiva é que se traz para a reflexão como esses referenciais culturais estão sendo trabalhados nas aulas de Educação Física, em escola pública, observando o encontro e o embate com as igrejas cristãs, notadamente as [neo]pentecostais e problematizando com a importância da garantia da laicidade da escola pública.

\section{A Educação Física, a Escola Laica e as Igrejas Cristãs}

Como material de análise, usou-se um caso ocorrido em uma escola pública estadual do Rio de Janeiro, com turmas do nono ano do Ensino Fundamental para desenvolver este estudo.

“Isso é macumba!" foi a expressão usada recorrentemente por estudantes (entre outras de sentidos pejorativos similares, como "isso é candomblé", ou mesmo "isso é do demônio" ou "do capeta"), no meio de seis turmas de nono ano (com aproximadamente 50 estudantes 
em cada uma) em que o professor resolveu tratar em suas aulas de Educação Física, da diversidade cultural brasileira, usando como perspectiva os três referenciais culturais considerados clássicos para se falar de população brasileira: os referenciais indígenas, europeus e africanos. Afinal, conforme citado em Vainfas (1999), “[Karl Von] Martius afirmou que a chave para se compreender a história brasileira residia no estudo do cruzamento das três raças formadoras de nossa nacionalidade - a branca, a indígena, a negra" (p.8). Desde então os estudos ora fortalecem esta perspectiva, ora a criticam, tornando-se um marco clássico no debate sobre a formação da população brasileira.

Só muito recentemente na história da Educação Física, a partir da década de 1980, é que tem sido discutida a expansão dos referenciais teóricos da área, ainda fortemente atrelados à tendência pedagógica esportivista - e como tal modelo se remete ao referencial europeu de esporte, estas aulas estariam quase que exclusivamente trabalhando estes referenciais em detrimento de outros. Estes "outros", neste debate, seriam os referenciais culturais indígenas e africanos. De maneira similar, Costa (2006) nos ajuda a entender as formas de constituição desses "outros" na formação da nação brasileira:

A [forma] mais evidente é que o outro ou os outros da nação não eram, na maior parte dos casos, grupos situados fora das fronteiras geográficas do país. Este lugar de "outro" da nação foi ocupado por grupos que compartilhavam do território nacional. [...] Atribuía-se, ora aos indígenas, ora aos afro-descendentes, ora àqueles identificados como mestiços uma inferioridade [não só] intelectual inata e, portanto, uma incapacidade imutável para fazer parte da nação [...] que se queria construir (p.134, grifos nossos).

Esses outros precisavam sumir, de uma forma ou de outra, corporal e culturalmente, para que a população brasileira cada vez mais se fizesse próxima do ideal europeu, cada vez mais branca. Não é de se estranhar que pouco se questiona sobre o uso desses referenciais culturais como ferramenta pedagógica. Ainda são valorizados prioritariamente os referenciais europeus, e somado a isso, reforça-se que estes "outros" referenciais não seriam "benéficos" ou até "úteis" na formação da população brasileira - ao contrário, seriam "prejudiciais",iii.

Por conseguinte, para que trabalhá-los nas aulas de Educação Física escolar? Quais heranças corporais e de movimento seriam desejadas oficialmente e pelas elites brancas para que estudantes as tivessem como referência positiva? E quais seriam aqueles referenciais que precisariam desaparecer simbólica e materialmente, ou, "ao menos", serem considerados ruins e inferiores? 
Enquanto se trabalha questões relacionadas ao esporte tudo é encarado com “naturalidade" e com certa "neutralidade", como um conteúdo legítimo da Educação Física. Entretanto, ao pautar atividades curriculares que trazem para conhecimento e o reconhecimento das turmas alguns referenciais africanos ou indígenas há/houve resistência e preconceito, normalmente por parte das turmas praticantes de religiões cristãs evangélicas [neo]pentecostais.

Quais poderiam ser os motivos dessa rejeição? Como era a população dessa escola? Em termos de uma maioria, temos tanto o corpo de pessoas trabalhadoras e profissionais da educação, quanto o corpo discente identificando-se religiosamente como cristãos, sendo que entre as diversas ramificações, observa-se uma maioria pentecostal. Curiosamente, esses mesmos sujeitos também podem ser identificados como negros (fenotipicamente, pretos e pardos), em quase sua totalidade.

Essa escola se localiza no Parque Lafayete, perto do Centro de Duque de Caxias-RJ (Primeiro Distrito deste município), atendendo, em sua maioria, à população de São João de Meriti e de Caxias. Fenotipicamente, podem ser identificados traços africanos e indígenas na população escolar, em geral. Há todo tipo de situação econômica presente entre os estudantes: há uma parte que é desprovida de renda estável, e outras que até possuem mais de uma casa, como as de veraneio em outros municípios do estado. Desde 2008 (época em que o professor começou a trabalhar na escola), e cada vez mais regularmente, há eventos no interior da escola (e com a devida autorização da Direção) de cunho declaradamente religioso, de confissão cristã pentecostal, com o título "Encontro com Deus", utilizando espaços e momentos comuns ou de aula, especialmente a quadra, para sua realização. Há ainda uma "propaganda" com papéis colados nas paredes e estímulo para a participação professado pela Coordenação de Turno/Direção (estes eventos normalmente aconteciam no turno da noite).

Juntamente com debates sobre racismo, discriminação, preconceito, algumas expressões culturais com referenciais africanos e indígenas foram propostas para a vivência das turmas, com o intuito de provocar a reflexão e problematização acerca desses temas. Entre alguns dos exemplos estão: as Cirandas de Pernambuco e do Rio de Janeiro, o Mineiro-pau, o Maculelê, a Capoeira. Entre os critérios de escolha estavam manifestações que pudessem ser usadas para problematizar questões locais, regionais e nacionais, trazendo temas raciais para o debate, juntamente com preconceitos e discriminações. Uma parte das intervenções era a própria vivência dessas expressões e, em outra parte, buscava-se um debate sobre a ausência das mesmas na escola e nas aulas de Educação Física, mostrando a prioridade do esporte e como este servia como referencial branco europeu (valorizado e tido como legítimo na escola 
e nas aulas de Educação Física) e a marginalização daquelas expressões culturais, por serem referenciais culturais africanos ou indígenas.

Mesmo desconhecendo-as, havia uma rejeição categórica a essas expressões, sendo demonstrada pela negação às mesmas, muitas vezes com um boicote às aulas. Contudo, a participação nas aulas, neste caso, participação nas vivências, fazia parte da avaliação de cada estudante. Do mesmo modo que cada componente avalia baseado em conteúdos, em participação e em envolvimento, com a Educação Física não seria diferente.

Assim sendo, temos alguns desdobramentos: (1) tais conteúdos (o racismo e as questões africanas e indígenas) são obrigatórios e precisam ser trabalhados em aulas (não havendo, assim, uma escolha ou uma isenção desses conteúdos por parte de cada estudante); (2) considerando que "macumba", neste caso específico, seja um termo pejorativo e negativamente utilizado por alguns segmentos cristãos para designar qualquer tipo de religiosidade africana ou similar, o mesmo foi usado para designar também qualquer outra expressão cultural com referencial africano ou indígena e; (3) mesmo sendo observado que na escola pública não se ensina religião (apesar do Ensino Religioso estar presente na rede estadual), pois é laica, ainda que o fizesse, estas expressões culturais vivenciadas nas aulas não fariam parte de qualquer religião de matriz africana.

Do mesmo modo que desde o início da colonização portuguesa no Brasil, a Igreja Católica "demonizou" as culturas dos "outros", este processo que testemunhamos hoje de manutenção de preconceitos é similar. Citando o Observatório da Laicidade do Estado - OLE (2011a):

A violência simbólica foi a tônica da evangelização, que utilizou formas sofisticadas, como o teatro dos missionários, e figuras de alta eficácia simbólica, como a invenção de Tupã para facilitar a assimilação da figura do Deus Cristão. Contra os africanos escravizados, a violência material que marcava sua condição dispensou maiores esforços com a violência simbólica (p.1).

As ramificações cristãs pentecostais vêm demonizando as culturas africanas, não só aquelas referentes às religiosidades de matrizes africanas, mas especialmente estas aqui apontadas. Qualquer expressão que tenha referência cultural africana (e as referências indígenas entram misturadas nessas categorizações) é tida como feia, ruim, inferior, sinal de passado que deve ser esquecido diante de um presente e um futuro em direção ao que seria belo, bom e superior, notadamente o deus cristão, branco, europeizado, que deveria ser seguido. Tudo que afastaria a pessoa deste deus seria "do demônio". 
"Diz o preconceito que tudo que é do negro não presta, ainda mais quando se trata de uma religião, de uma falsa religião [...] de magia, macumba e magia negra” (p.120), reforça Prandi (1995). Ainda o mesmo autor comenta em seguida:

\begin{abstract}
Algumas denominações pentecostais de origem muito recente e grande sucesso junto às massas, como a Igreja Universal do Reino de Deus, Deus é Amor e A Casa da Benção, atraem boa parte de sua clientela pregando contra a umbanda e o candomblé, identificados como fonte do mal [...] O conflito entre pentecostais e afro-brasileiros é aberto e mesmo incentivado por lideranças pentecostais (p.120).
\end{abstract}

Mais uma vez, como outrora a Igreja Católica fez em seu apoio à dominação européia sobre os povos indígenas e africanos, elege-se o referencial da religião cristã como o verdadeiro e que deve prevalecer e ser dominante diante de manifestações religiosas “inferiores”. Manifestações dos outros, daqueles povos que seriam o alvo de sua dominação. $\mathrm{O}$ embate se concretiza em definitivo entre segmentos cristãos pentecostais diante de religiosidades africanas.

Um exemplo que já se tornou ícone deste embate é o que Caputo (2012) chamou em seu livro de "os crimes do bispo Macedo e a responsabilidade das empresas jornalísticas", sobre o uso descabido pelo bispo e pela Igreja Universal do Reino de Deus das fotos que a autora tirara de crianças praticantes de candomblé. A própria autora relata:

Foi o que aconteceu em 1993, quando a Editora Gráfica universal, do Grupo Universal do Reino de Deus, comprou as fotos da matéria que fiz para $\mathrm{O}$ dia e publicou no jornal Folha Universal uma matéria com o título "Filhos do Demônio".

Milhares de jornais com as fotos de Ricardo Nery, Paula dos Santos e Tauana dos Santos foram espalhados pela Baixada Fluminense e em outras regiões do estado do Rio. Três anos depois, a mesma editora lançou a $13^{\mathrm{a}}$ edição (1996) do livro Orixás, Caboclos e Guias - Deuses ou Demônios?, escrito pelo bispo Edir Macedo. Na tiragem de 50 mil exemplares, outra vez a reprodução das fotos da reportagem que fiz. Paula e Ricardo apareciam sob a legenda: "essas crianças, por terem sido envolvidas com os orixás, certamente não terão boas notas na escola e serão filhos-problemas na adolescência". A capa dessa edição ainda comemora 2 milhões de exemplares vendidos" (p.181).

Percebendo o atual momento histórico e político é possível investigar a nuance desses preconceitos, com base nessas campanhas cristãs (especialmente) pentecostais que consideram diversas expressões culturais africanas (enfaticamente) como expressões "do 
mal”, criadas por forças "demoníacas", procurando, dessa forma, ser um contraponto "do bem" a essas expressões ${ }^{\mathrm{iv}}$. Uma possível consequência dessas ações na Educação é o impedimento e/ou o aumento de dificuldades para se trabalhar de acordo com a $L D B$, em outras palavras, de se conhecer essas culturas africanas e indígenas, para poder valorizá-las, respeitá-las, podendo gerar identificações e reconhecimentos por parte da comunidade escolar. E por um caminho mais profundo, de problematizar o racismo que baseia nossa sociedade, especialmente diante dessas "outras" populações - as descendentes de africanos e indígenas.

O que garante certa possibilidade de se trabalhar essas culturas e suas expressões é a laicidade do Estado e, por consequência, da escola pública. De acordo com o Glossário do Observatório da Laicidade do Estado - OLE (2011b),

A posição laica é imparcial em matéria de religião, seja nos conflitos ou nas alianças entre as crenças religiosas, seja diante da atuação dos não crentes. A posição laica não implica a rejeição de qualquer religião. Implica, isto sim, o não envolvimento no proselitismo nem nas disputas entre elas pela fé dos crentes, nem na crítica a qualquer delas ou a todas elas pelos não crentes (p.3-4).

Contudo, o que temos presenciado configura-se uma reação de forças religiosas institucionalizadas em disputas de poder ao perceberem algumas situações em que foram aumentados os riscos à sua própria "sobrevivência". Nas palavras de Senra (2010), algumas destas situações seriam

a expansão das forças do Estado, a mobilidade social, a urbanização, a difusão de ideologias não religiosas ou antirreligiosas. O que era uma tradição, cuja sobrevivência não sofria ameaças diretas, precisou se tornar mais consciente, mais mobilizada, com um discurso mais sofisticado, com uma organização capaz de disputar espaços ou negociar condições. Podemos observar essa capacidade nos conceitos que a Igreja Católica, velha adversária dos Estados liberais, adotou a partir de meados do século 20. Ela passou a admitir a existência de um Estado laico, portador da laicidade (uma espécie de neutralidade diante das opções religiosas dos cidadãos, respeitando o direito deles ao exercício da consciência religiosa), mas continuou a combater o laicismo (a imposição de concepções laicas por parte do Estado, exercida, por exemplo, na negação do direito ao ensino religioso nas escolas públicas). Por trás de uma diferença conceitual aparentemente sutil, os católicos organizaram um discurso, materializado em práticas políticas em vários Estados (p.2). 
Dessa forma, pensar um Estado laico é pensar um Estado democrático. É desenvolver políticas, que são públicas, voltadas para toda a população. Esta população é, como nos aponta Fischmann (2008),

ao mesmo tempo, os indivíduos que compõem grupos religiosos, espirituais ou filosóficos, [que] são também herdeiros de uma cidadania, de um país que vem arduamente se construindo como democrático, em um mundo que busca de forma aflita construir referencias universais de proteção à dignidade humana, de respeito aos direitos de todos (p.17).

E é nesta cidadania que se deve focar qualquer política. E a escola, em especial a escola pública, que é mantida pelo Estado, deveria seguir de forma coerente com esta noção de cidadania em suas intervenções, que sempre são políticas e pedagógicas. E tem sido esta mesma escola pública a mais atingida pelas políticas defendidas pelos setores religiosos cristãos posicionados de forma conservadora, sabotando ações focadas no desenvolvimento da democracia na escola, e investindo, em contrapartida, em ações que fortalecem suas doutrinas e suas visões de mundo ${ }^{\mathrm{v}}$. Católicas ou pentecostais, ambas as vertentes do cristianismo têm influenciado tanto a base da população, como também consolidando cargos eletivos e influência política em todo o país - formando, expressivamente, "bancadas cristãs" no Congresso Nacional e em outras instâncias governamentais. Pode-se observar as últimas eleições, de 2014, como problematiza Passos (2014), em que foi eleito "o congresso mais conservador desde a ditadura" (p.1) ${ }^{\mathrm{vi}}$.

O debate de Fischmann (2008) aponta para um modelo de escola laica, democrática, que é necessariamente não doutrinária ou tendenciosamente direcionada para qualquer religião ou visão de mundo que não seja em pró do coletivo, do comum e do público. Bem diferente das atuais políticas públicas na educação, que mantém e estimulam o ensino religioso, seja através da oficialização enquanto componente curricular ou pela facilidade/permissão de certas intervenções declaradamente doutrinárias nos tempos e espaços escolares. Para a autora,

à educação escolar caberá a formação para o exercício reflexivo, a capacidade crítica e argumentativa; também, a escola deverá propiciar oportunidades para que crianças e jovens desenvolvam a capacidade buscar elementos e subsídios para uma decisão informada, assim como a capacidade de compreender as repercussões das próprias decisões sobre os outros. São capacidade humanas que independem de conteúdos religiosos, mas da ética universal (p.35). 
Diante de tudo isso, a defesa da escola pública e laica é uma das grandes questões de nosso país, em que a cada momento são dados golpes, ora sutis, ora facilmente identificados e percebidos pela população. Em um instante, verbas públicas financiam instituições de ensino privadas, favorecendo estas e precarizando o próprio ensino público; em outro, ocorre a abertura para diferentes intervenções na escola pública pelas vertentes cristãs, como o Catolicismo (que vem influenciando a República brasileira desde sua geração, com a separação entre o Estado e a Igreja Católica) e como o Protestantismo, nas suas manifestações Evangélicas Pentecostais, que disputam espaço e fiéis, em um campo religioso em que o Catolicismo é predominante. Conforme Pierucci (2004), "pelo viés dos números absolutos, o catolicismo continua amplamente majoritário e se destaca nas tabelas do IBGE contra o fundo das outras confissões, minoritárias" (p.18) ${ }^{\mathrm{vii}}$.

A defesa da escola - pública e laica - também representa uma luta pela própria democratização do Brasil. Espelhando isso na democratização da própria Educação. É algo importante para atentarmos, já que (somando a constante e conhecida influência política da Igreja Católica) o crescimento do Pentecostalismo se dá especialmente entre as populações mais pobres (em sua maioria, negras e nordestinas), e que grande parte dessas populações é justamente a que é mais atendida pela escola pública. Através de dados estatísticos, Pierucci (2004) demonstra como estas mudanças, têm acontecido:

foi nos últimos vinte anos [1980-2000] que as taxas de crescimento do conjunto dos evangélicos mais subiram. E foi sobretudo nos anos de 1990 que eles alcançaram um crescimento em tudo e por tudo extraordinário, crescendo a uma taxa praticamente de $100 \%$ no intervalo de um decênio. Dobraram de tamanho. Em números absolutos, saltaram de treze para 26 milhões. Semelhantemente aos evangélicos, é nas duas últimas décadas do século XX que o grupo dos "sem religião" passa a apresentar taxas maiores de crescimento. Categoria quase insignificante até 1980, passam daí em diante a proliferar num ritmo de fazer inveja a qualquer grupo "com religião". Hoje são nada menos que $7,3 \%$ da população. No Estado do Rio de Janeiro, os "sem religião" são hoje mais de $15 \%$, o que ajuda a deprimir aí a taxa de católicos para o ponto mais baixo do País: $57,2 \%$ (pp.21-22).

O mesmo autor resume o quadro de forma enfática: “o catolicismo em declínio, os pentecostais e os sem religião em escalada" (p.19)!

É pertinente relacionar este fato com uma pretensa disputa de fiéis e de espaços (materiais ou políticos, por exemplo), em que podemos perceber as diferenças entre estas duas grandes vertentes do Cristianismo. 
Neste momento, a Católica vem muito mais administrando sua posição política na sociedade brasileira, mantendo privilégios e expandindo seu poder com certo suporte do Estado (verbas para escolas e igrejas, feriados, isenções fiscais, etc.); enquanto que as Pentecostais não possuem esse status e precisam constantemente ser "agressivas" para se firmar, tanto contra a Católica (em posição majoritária e dominante), tanto contra as religiosidades de matrizes africanas, como a Umbanda e o Candomblé, no Rio de Janeiro (no que tange às populações mais pobres, na tentativa/intenção de conversão destes fiéis) ${ }^{\text {viii }}$.

Contudo, diante do tratamento dado às culturas africanas (em especial) e indígenas, estas vertentes do Cristianismo se diferem, neste caso, apenas pelos momentos históricos em que exercem suas ações, já que a Igreja Católica as "demonizou" durante a colonização, de similar forma que as Pentecostais fazem hoje. O tratamento oficial do Estado (lembrando da influência da Católica neste) só tem mudado depois de muita luta e organização social de movimentos representativos dessas culturas e populações, outrora discriminadas. Ainda sim, se não as "demoniza", muitas vezes as "coisificam”, inferiorizando suas expressões e seus valores através de uma relação pejorativa de folclorização destes referenciais culturais. Conforme aponta Araújo (2011),

[...] ao se folclorizar a cultura, folcloriza-se com ela, o indivíduo e o grupo racial. Examinada deste ponto de vista, a folclorização é a parte de um mecanismo histórico de produção do homem-espetáculo ou espetaculoso, do ser exótico e leviano, e, como tal incorporado à dimensão não-séria histriônica e mágica — da vida nacional. Opondo-se ao país operoso, racional, capitalista, esta cultura é expressão e suporte do que há de amalandrado, mágico, inconsequente e preguiçoso da vida nacional (p.4).

Tais expressões também representariam tudo de ruim e, seguindo o mesmo pensamento, não serviriam para serem estudadas na escola. Assim, se estrutura a dificuldade em lidar com a diversidade cultural, e, com a articulação cristã muito consolidada e mantendo essa postura aversiva, as dificuldades se agravam: tanto no nível dos trâmites políticos, tanto no nível estritamente pedagógico.

\section{Apontamentos Finais}

Não é só pela Educação Física que tudo isso atravessa, é um quadro que permeia a Educação e outras políticas públicas especialmente voltadas para "minorias" da população brasileira (por exemplo, as relacionadas com direitos reprodutivos e sexuais, para mulheres e LGBTs $^{\text {ix }}$ : questões como o aborto e a união civil de homoafetivos, que recaem em barreiras 
religiosas - normalmente através das "bancadas cristãs" - dificultando o debate e muitas vezes impedindo o avanço dessas políticas públicas). É para desenvolvermos uma crítica contundente diante de manobras políticas que favorecem a instalação nas redes públicas de ensino, de componentes como a Educação Religiosa (o caso mais recente é a abertura de edital para o concurso para esse componente, no município do Rio de Janeiro, em 2011). Afinal, a quem favorece isso? Entre as possibilidades de resposta, o Ensino Religioso favorece a disseminação das religiões cristãs, especialmente o Catolicismo (como atestamos com o trabalho [já citado] de Antônio Pierucci, é majoritário na população brasileira, fluminense e carioca) e as Evangélicas, que têm crescido constante e significativamente nas últimas décadas - em especial os setores Pentecostais. Entre as explicações para essas manobras, estariam evidentes (1) o apoio e financiamento público de diversas religiões, que são instituições privadas, num Estado laico (será laico mesmo?); (2) o favorecimento "acadêmico", em que normalmente os concursos exigem níveis de formação superiores tendenciosamente cristãos (como é o caso da formação em Teologia) e; simultaneamente, (3) um desfavorecimento "tradicional", quase que excluindo dos concursos a formação com base nas matrizes africanas por conta de esta formação não ser acadêmica ou sistematizada nestes moldes, ao ser perpassada, básica e fundamentalmente, pela oralidade, ou mesmo por essa população ser mais pobre e/ou ter mais dificuldade de continuar a vida acadêmica/escolar, ou então pela não necessidade em seu modo de funcionamento, de procurar converter fiéis (isto sim, presente em todas as cristãs). Isso sem contar com outros tipos de desdobramentos que estariam obscuros no meio de todo esse processo.

Por conta de todos esses apontamentos, parece (e acreditamos) que o trabalho com diversidade cultural na escola pública é um caminho para o desenvolvimento do conhecimento, do reconhecimento e do respeito e valorização de várias das culturas presentes em nossa sociedade, especialmente aquelas que historicamente vêm sendo discriminadas e desvalorizadas, como é o caso das manifestações africanas e indígenas. É um caminho também que pretende servir de auxílio à Educação Física na busca de sua identidade enquanto intervenção pedagógica, para além da questão esportivista e do referencial europeu de corpo e movimento, com especial potencial de problematizar questões como o racismo, preconceito e discriminação presentes em nossa sociedade. E mais do que isso, uma forma de lutar pela Educação, pela escola pública, pelo Estado e sociedade laicos, pela construção cotidiana de uma democracia no Brasil.

Toda educação deve, ou pelo menos deveria, ser uma educação em direitos humanos, em que todo componente curricular precisasse ter o foco numa educação em direitos 
humanos. De nada serviria uma educação, nessa perspectiva, que não pautasse o exercício de cidadania, de participação, de respeito ao outro, fazendo com que a questão racial fosse mais que transversal: seria integrante de qualquer componente curricular, e, de forma similar, também seriam as questões sobre gênero, sexualidade, geração, classe, origem, religiosidade, entre outros temas que também são chamados desta forma.

\section{Referências Bibliográficas}

ARAÚJO, Zezito de. Folclorização e Significado Cultural do Negro. Disponível em: www.ideario.org.br/neab/kule2/Textos\%20kule2/Zezito.pdf Acesso em: 10 dez. 2011.

BRASIL. Presidência da República/Casa Civil. Constituição da República Federativa do Brasil de $1988 . \quad$ Disponível em: http://www.planalto.gov.br/ccivil_03/constituicao/constitui\%C3\%A7ao.htm Acesso em: 25 ago. 2009.

. Lei n.9394 (LDB), de 20 de dezembro de 1996. Disponível em: www.planalto.gov.br/ccivil_03/Leis/_L9394.htm Acesso em: 25 ago. 2009.

BRASIL. Presidência da República/Casa Civil. Lei n.10.639, de 9 de janeiro de 2003. Disponível em: http://www.planalto.gov.br/ccivil_03/Leis/2003/L10.639.htm Acesso em: 25 ago. 2009.

BRASIL. Presidência da República/Casa Civil. Lei n.11.465, de 10 de março de 2008. Disponível em: http://www.planalto.gov.br/ccivil_03/_Ato2007-2010/2008/Lei/L11645.html Acesso em: 25 ago. 2009.

CAPUTO, Stela Guedes. Educação nos terreiros: e como a escola se relaciona com crianças de Candomblé. Rio de Janeiro: Pallas, 2012.

COSTA, Sérgio. “A agonia do Brasil mestiço". In: Dois Atlânticos: teoria social, antiracismo, cosmopolitismo. Belo Horizonte: Ed. UFMG, 2006, pp.131-150.

FELICIANO, Deputado Pastor Marcos. Projeto de Lei 8099 de 2014. Disponível em: http://www.camara.gov.br/proposicoesWeb/fichadetramitacao?idProposicao=777616 Acesso em: 21 dez. 2014.

FISCHMANN, Roseli. Estado Laico. São Paulo: Memorial da América Latina, 2008. (Coleção Memo).

INSTITUTO BRASILEIRO DE GEOGRAFIA E ESTATÍSTICA - IBGE. Censo 2010: número de católicos cai e aumenta o de evangélicos, espíritas e sem religião. Disponível 
censo view $=$ noticia\&id $=1 \&$ idnoticia $=2170 \& \mathrm{t}=$ censo- 2010 -numero-catolicos-cai-aumentaevangelicos-espiritas-sem-religiao Acesso em: 21 dez. 2014.

OBSERVATÓRIO DA LAICIDADE DO ESTADO - OLE. Conceituação: Campo religioso: harmonia ou conflito? Disponível em: http://www.neppdh.ufrj.br/ole/conceituacao2.html Acesso em: 12 out. 2011a.

OBSERVATÓRIO DA LAICIDADE DO ESTADO - OLE. Conceituação: Glossário. Disponível em: http://www.nepp-dh.ufrj.br/ole/conceituacao1.html Acesso em: 12 out. 2011 b.

PASSOS, Najla. Congresso eleito é o mais conservador desde o fim da ditadura, diz DIAP. Disponível em: http://www.cartamaior.com.br/?/Editoria/Politica/Congresso-eleito-eo-mais-conservador-desde-o-fim-da-ditadura-diz-Diap/4/31948 Acesso em: 19 dez. 2014

PRANDI, Reginaldo. Raça e Religião. Novos Estudos - CEBRAP. n.42: São Paulo, 1995. pp.113-129.

PIERUCCI, Antônio Flávio. "Bye bye, Brasil": o declínio das religiões tradicionais no Censo 2000. Estudos Avançados. São Paulo: vol. 18, nº 52, dezembro de 2004, pp. 17-28.

SENRA, Alvaro de Oliveira. Laicismo e laicidade. Boletim ASA. n ${ }^{\circ}$ 123, mar-abr de 2010. Disponível em: http://www.asa.org.br/boletim/123/123_h2.html Acesso em: 12 out. 2011.

TONI, Flávia Camargo. Missão: as pesquisas folclóricas. Disponível em: http://www.sescsp.org.br/sesc/hotsites/missao/textos_frameset.html Acesso em: 10 dez. 2011.

UNESCO. Convenção sobre a proteção e a promoção da diversidade das expressões culturais. $\quad$ Paris: UNESCO, $2005 . \quad$ Disponível em: http://unesdoc.unesco.org/images/0015/001502/150224por.pdf Acesso em: 13 mai. 2010.

VAINFAS, Ronaldo. Colonização, miscigenação e questão racial: notas sobre equívocos e tabus da historiografia brasileira. Tempo, n.8. Rio de Janeiro: 1999, pp. 7-22.

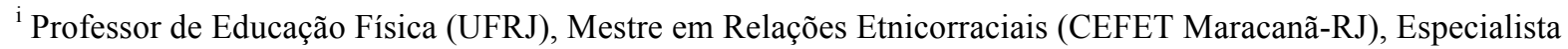
em Gênero e Sexualidade (CLAM-UERJ) e em História da África e da Diáspora Africana no Brasil (FIS).

Docente da Rede Pública de Ensino, na Secretaria Municipal de Educação - SME, da Prefeitura da Cidade do Rio de Janeiro.

ii Tal evento/momento e seus desdobramentos ajudam a compreensão das noções de "cultura brasileira" e "identidade brasileira", no século XX. Missões similares foram inspirações para Andrade, como as feitas por Debret (1768-1848) e Langsdorff (1774-1852) no século XIX.

iii Porque vinculados à ideia de atraso, enquanto referenciais culturais europeus estão ligados à ideia da modernidade.
} 
${ }^{\text {iv }}$ Historicamente, a Igreja Católica foi a instituição que, primeiramente, combateu as religiões de matriz africana dessa forma (podemos aqui fazer um recorte: em termos de colonização no Brasil); assim como o protestantismo e o espiritismo. No geral, eram consideradas inferiores diante dessas outras.

` O exemplo mais recente é o Projeto de Lei, de 2014, de autoria do Deputado Pastor Marco Feliciano em que "ficam inseridos na grade curricular das Redes Pública e Privada de Ensino, conteúdos sobre Criacionismo". Na justificação há o argumento a seguir: "As crianças que frequentam as escolas públicas tem se mostrado confusas, pois aprendem nas suas respectivas escolas noções básicas de evolucionismo, quando chegam a suas respectivas Igrejas aprendem sobre o criacionismo em rota de colisão com conceitos de formação escolar e acadêmica" (p.2).

vi "O levantamento preliminar do DIAP [Departamento Intersindical de Assessoria Parlamentar ] captou 52 pastores, bispos e cantores de música gospel eleitos para a Câmara Federal, contra 70 em 2010. Mas o órgão ainda vai refinar a pesquisa para avaliar a religião dos eleitos sem grande projeção nacional. 'São 38 reeleitos e 14 novos, mas entre eles estão nomes de grande projeção entre esse setor, que defendem posições regressivas em relação ao aborto e à homofobia, por exemplo', analisa o diretor [de Documentação do órgão, Antônio Augusto Queiroz]" (PASSOS, 2014, p.1). Soma-se também o aumento da bancada ruralista, de segurança/militar e de empresarial a esta composição conservadora.

vii $\mathrm{O}$ censo 2010 do IBGE também reforçou as tendências que vinham sendo demonstradas nos outros censos. "Os resultados do Censo Demográfico 2010 mostram o crescimento da diversidade dos grupos religiosos no Brasil. A proporção de católicos seguiu a tendência de redução observada nas duas décadas anteriores, embora tenha permanecido majoritária. Em paralelo, consolidou-se o crescimento da população evangélica, que passou de 15,4\% em 2000 para 22,2\% em 2010. Dos que se declararam evangélicos, 60,0\% eram de origem pentecostal, $18,5 \%$, evangélicos de missão e $21,8 \%$, evangélicos não determinados. A pesquisa indica também o aumento do total de espíritas, dos que se declararam sem religião, ainda que em ritmo inferior ao da década anterior, e do conjunto pertencente às outras religiosidades" (p.1).

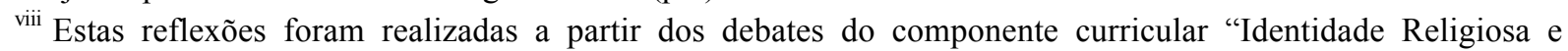
Diversidade Cultural e Étnica no Brasil”, do PPRER/CEFET-RJ, com o professor Alvaro Senra, especialmente na última aula do curso, no dia 30 de novembro de 2011.

${ }^{\text {ix }}$ Lésbicas, gays, bissexuais, transsexuais, travestis e transgêneros 